\title{
Multidimensional infrared spectroscopy reveals the vibrational and solvation dynamics of Isoniazid
}

\author{
Daniel J. Shaw, ${ }^{a, b}$ Katrin Adamczyk, ${ }^{a}$ Pim W.J.M. Frederix, ${ }^{a}$ Niall Simpson, ${ }^{a}$ Kirsty Robb, ${ }^{b}$
}

Gregory M. Greetham, ${ }^{c}$ Michael Towrie, ${ }^{c}$ Anthony W. Parker, ${ }^{c}$ Paul A. Hoskisson, ${ }^{b}$ Neil T. Hunt ${ }^{a *}$

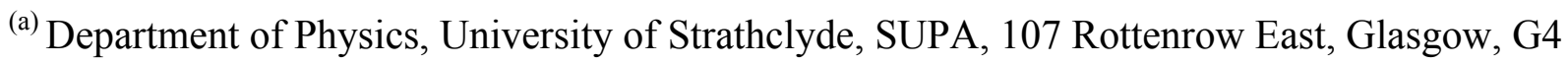
0NG, United Kingdom

(b) Strathclyde Institute for Pharmacy and Biomedical Sciences (SIPBS), University of Strathclyde, 161 Cathedral Street, Glasgow, G4 0RE, United Kingdom

(c) Central Laser Facility, Research Complex at Harwell, Rutherford Appleton Laboratory, Didcot, OX11 0QX, United Kingdom 
Abstract: The results of infrared spectroscopic investigations into the band assignments, vibrational relaxation and solvation dynamics of the common anti-tuberculosis treatment Isoniazid (INH) are reported. INH is known to inhibit InhA, a 2-trans-enoyl-acyl carrier protein reductase enzyme responsible for the maintenance of cell walls in Mycobacterium tuberculosis but as new drug-resistant strains of the bacterium appear, next-generation therapeutics will be essential to combat the rise of the disease. Small molecules such as INH offer the potential for use as a biomolecular marker through which ultrafast multidimensional spectroscopies can probe drug binding and so inform design strategies but a complete characterization of the spectroscopy and dynamics of INH in solution is required to inform such activity. Infrared absorption spectroscopy, in combination with Density Functional Theory calculations, is used to assign the vibrational modes of INH in the $1400-1700 \mathrm{~cm}^{-1}$ region of the infrared spectrum while ultrafast multidimensional spectroscopy measurements determine the vibrational relaxation dynamics and the effects of solvation via spectral diffusion of the carbonyl stretching vibrational mode. These results are discussed in the context of previous linear spectroscopy studies on solid-phase INH and its usefulness as a biomolecular probe.

Keywords: Infrared spectroscopy, ultrafast 2D-IR spectroscopy, vibrational dynamics, isoniazid, spectral diffusion 


\section{Introduction}

Isonicotinic acid hydrazide (INH), more commonly known as Isoniazid, was first used to treat Mycobacterium tuberculosis, the cause of tuberculosis, over sixty years ago and remains one of the front line therapeutics employed to fight the disease. ${ }^{1,2}$ The mode of action of INH is to inhibit the single active site found within InhA, the 2-trans-enoyl-acyl carrier protein reductase enzyme that forms an essential part of the mycolic acid biosynthesis system within M. tuberculosis bacteria. ${ }^{3,4} \mathrm{INH}$, the structure of which is shown in Fig. 1, is a pro-drug, requiring biochemical activation prior to becoming effective. This occurs through oxidation by an oxidase-peroxidase enzyme (KatG) leading to loss of the $-\mathrm{NH}-\mathrm{NH}_{2}$ moiety and binding of the resultant radical anion to the nicotinamide group of nicotinamide adenine dinucleotide hydride (NADH) to form the biologically-active INH-NAD adduct, which binds to InhA. ${ }^{5}$

Despite the existence of drugs such as INH, tuberculosis continues to be a major global health problem. ${ }^{6}$ In particular, the rise in incidences of drug-resistant forms of the bacterium represents a challenge that urgently needs to be addressed. There are indications that one resistance mechanism to INH results from single point mutation of InhA (S94A) near the INH-NAD binding site. ${ }^{3}$ Thus, the design of new therapeutics will be informed by an understanding of molecularlevel interactions in the binding of INH-NAD.

One aspect of this problem that remains unaddressed is the role played by fast molecular dynamics in the drug binding process. These dynamics arise from protein fluctuations and $\mathrm{H}$ bond-related dynamics of both biomolecule and solvent but obtaining site specific measurements of such processes within the binding site of proteins or enzymes is a significant experimental challenge. Ultrafast spectroscopy methods, in particular 2D-IR spectroscopy, are beginning to 
offer useful new insights into the problem. ${ }^{7,8}$ For example, it has been shown that various strategies employing spectroscopic probes can enable 2D-IR measurements to extract local information from complex systems. These probes include isotopically-labelled peptide links placed within the structure of biomolecules, which have been used to obtain structural ${ }^{9}$ and solvation $^{10}$ information including examples relating to fibril formation ${ }^{11,12}$ or the action of transmembrane channels. ${ }^{13,14}$ Alternatively, small molecule ligands have been employed to investigate drug binding ${ }^{15}$ and widely in the haemoprotein family to determine structural dynamics ${ }^{16} 17,18$ and local solvent motion. ${ }^{19,20}$ It has however become clear that no single probe method will work for all biological problems and the development of system-specific tools is often needed. $^{21,22}$

In the case of the INH-NAD-InhA system, it is unfortunate that the INH-NAD complex cannot be easily isolated outside the biological system for study and manipulation but the small molecule drug INH offers the opportunity for use as a local probe, either in its standard form or as a platform for development. To underpin this process, a full understanding of the spectroscopy of INH is required. Several studies of the molecule have been reported using linear spectroscopy and theoretical modelling to assign the IR spectrum but these are almost universally in the solid phase or matrix-isolated samples. ${ }^{2,23,24,25}$ No assignment has been reported under the solution phase, deuterated conditions necessary for biomolecular 2D-IR spectroscopy. In addition, questions have arisen as to the structure of INH. Crystallography has indicated a cis arrangement for the CO-NH$\mathrm{NH}_{2}$ unit (Fig. 1b) ${ }^{26}$ and this has been supported by the most recent spectroscopy and density functional theory (DFT) studies ${ }^{24,25}$ but previous studies were based on the trans configuration (Fig. 1a). ${ }^{2,23}$ The difference between the two forms is the presence of an intramolecular H-bond between the $\mathrm{NH}_{2}$ and $\mathrm{C}=\mathrm{O}$ moieties. ${ }^{24}$ While this feature is academic in the case of binding to 
InhA, as it is lost in the activation of $\mathrm{INH}$, it may be important in take-up by the activating enzymes.

In this article we report the application of linear infrared absorption and ultrafast 2D-IR spectroscopies alongside DFT calculations to provide an assignment of the vibrational modes of INH in solution in the $1400-1700 \mathrm{~cm}^{-1}$ region. In addition, we report the vibrational relaxation dynamics and intra-mode coupling patterns observed and use 2D-lineshape analysis of the $\mathrm{C}=\mathrm{O}$ stretching mode to determine the solvation dynamics contributing to the spectral diffusion of this biochemically-active moiety. These results are discussed in the context of the molecular structure of INH in solution and its usefulness as a future probe of drug binding in InhA and will complement recent work on characterizing $\mathrm{NAD}(\mathrm{H})$ using multidimensional IR spectroscopy. ${ }^{22}$

\section{Experimental}

Isoniazid, deuterium oxide, and sodium phosphate buffer were all obtained from Sigma Aldrich and were used without further purification. Care was taken to ensure complete deuteration of all components of the samples prior to use. For all spectroscopy measurements, except where stated, an isoniazid concentration of $\sim 300 \mathrm{mM}$ was used and the sample was held between two $\mathrm{CaF}_{2}$ windows separated by a $50 \mu \mathrm{m}$ thickness PTFE spacer.

Fourier Transform (FT) IR Spectroscopy: All FT-IR spectra were acquired using a Bruker Vertex 70v FT-IR spectrometer operating with a resolution of $0.5 \mathrm{~cm}^{-1}$ and were the average of 20 scans. For temperature-dependent measurements a sample cell equipped with a heater was used to vary the temperature of the sample in $5^{\circ} \mathrm{C}$ increments with an accuracy of $\pm 1{ }^{\circ} \mathrm{C}$. 
Multidimensional IR Spectroscopy: The core of the spectrometer used for both ultrafast 2D-IR and IR pump-probe experiments was the ULTRA Ti:Sapphire laser system, ${ }^{27}$ which was used to pump an optical parametric amplifier (OPA) equipped with difference frequency mixing of the signal and idler beams. The resulting $\sim 3 \mu \mathrm{J}$ mid IR pulses were produced at a repetition rate of 10 $\mathrm{kHz}$ with $\leq 100$ fs duration; center frequency, $1550 \mathrm{~cm}^{-1}$ and bandwidth in excess of $300 \mathrm{~cm}^{-1}$.

Ultrafast 2D-IR spectra were collected using the FT-2D-IR method described previously. ${ }^{18,20,22,}$ ${ }^{28}$ Briefly, the mid IR pulses were arranged in a pseudo pump-probe geometry featuring a pair of collinear 'pump' pulses and a 'probe' pulse, which were spatially overlapped in the sample. The two pump pulses were separated by a variable delay time, $\tau$, which was controlled by a Michelson-type interferometer. The probe pulse was delayed in time with respect to the second pump pulse by the waiting time $\mathrm{T}_{\mathrm{w}}$, determined by an additional optical delay line. Magic angle relative polarization of the pump and probe pulses were used throughout to suppress the effects of molecular rotation, though the orientational relaxation time of $\mathrm{INH}$ was expected to be significantly longer than the vibrational lifetime of the modes studied. ${ }^{29}$ The probe pulse was frequency dispersed and detected using a spectrometer and 128 channel mercury-cadmiumtelluride (MCT) detector array to give the probe frequency axis of the 2D-IR spectrum with a spectral resolution of $1.4 \mathrm{~cm}^{-1}$. The data was obtained as a function of $\tau$ and the pump frequency axis of the 2D-IR spectrum recovered by Fourier Transformation. The field autocorrelation of a residual pulse pair from the interferometer incident on a single pixel MCT detector was used to accurately define the time at which the pump pulse-pair were coincident on the sample. To account for fluctuations in laser power, the signals were normalised using a reference beam that was dispersed and imaged onto a 64 channel MCT detector array. Residual pump-probe signals 
were removed via a chopper set to half the repetition rate of the laser positioned in the fixed arm of the interferometer.

For IR pump-probe experiments the same spectrometer was used but one of the two pump arms in the 2D-IR setup was blocked. The polarization of the pump pulse was varied with respect to that of the the probe pulse by means of a $\lambda / 2$ wave plate in order to conduct polarization-dependent measurements as described in the results section.

DFT calculations: DFT structure optimizations and vibrational mode frequency calculations for INH using both isomers shown in Fig. 1 were performed with the Gaussian 09 package using the B3LYP/6-311+G(d,p) combination of functional and basis set. ${ }^{30}$ A scaling factor of 0.9679 was applied to all vibrational frequencies as appropriate for this methodology. ${ }^{31}$ The effects of an aqueous solvent were included in the calculations using the application of a polarizable continuum model and all exchangeable protons were specifically replaced with deuterons to mimic the effects of $\mathrm{D}_{2} \mathrm{O}$ solvation. ${ }^{30}$

\section{Results and Discussion}

FT-IR spectroscopy: The $\mathrm{D}_{2} \mathrm{O}$-subtracted IR absorption spectrum of INH is shown in Fig. 2(a). In the $1400-1700 \mathrm{~cm}^{-1}$ region of the spectrum, which is the most widely used for protein 2D-IR spectroscopy, six bands are observable. The frequency and linewidth of these features have been extracted by fitting to Gaussian functions and are shown in Table 1. These can be broadly segregated into two groups by linewidth with two broader (width $\sim 20 \mathrm{~cm}^{-1}$ ) features located at 1644 and $1447 \mathrm{~cm}^{-1}$ being accompanied by narrower lines $\left(\sim 4-8 \mathrm{~cm}^{-1}\right)$ at $1608,1555,1502$ and $1415 \mathrm{~cm}^{-1}$. As the CO-NH-NH$H_{2}$ ring substituent would be expected to be more prone to $\mathrm{H}-$ bonding in aqueous solution, this suggests an assignment of the former group to the $\mathrm{C}=\mathrm{O}$ 
stretching $\left(1644 \mathrm{~cm}^{-1}\right)$ and $\mathrm{C}-\mathrm{N}$ stretching/NH bending $\left(1447 \mathrm{~cm}^{-1}\right)$ modes of the CO-NH-NH moiety, which are loosely analogous to the amide I' and II' modes found in peptides. The latter group is thus assigned to vibrational modes involving the pyridine ring.

These assignments are in good agreement with those derived from matrix isolation studies and crystalline samples of INH reported previously. ${ }^{24}$ Further support is provided by the results of DFT calculations, which are shown in Fig. 2(b) and in Table 1 for comparison. It is interesting to note that apparently slightly better agreement with the experimental band positions is obtained from the trans structure calculation, with the $\mathrm{C}=\mathrm{O}$ stretching and $\mathrm{CN}$ stretch $/ \mathrm{NH}$ bending modes being predicted to be lower in frequency in the cis structure relative to the trans isomer as a result of the intramolecular H-bond interaction. This is in apparent contradiction of calculations that show the cis isomer to be the lower in energy; ${ }^{24}$ a result that is also in agreement with our own calculations. It is important to bear in mind however that the absolute frequencies predicted by DFT for the $\mathrm{C}=\mathrm{O}$ stretching and $\mathrm{CN}$ stretch/NH bending modes will be highly susceptible to the strength of the intramolecular H-bond and it will be hard to predict the exact situation present in the solution phase. Thus, this outcome should not have too great a weight placed upon it.

The main area of difference between the solution-phase data reported here and previous work in the solid or matrix phases arises from the $\mathrm{NH}_{2}$ bending vibration, which was observed at $1628 \mathrm{~cm}^{-}$ ${ }^{1}$ in a Xe matrix. ${ }^{24}$ In $\mathrm{D}_{2} \mathrm{O}$ solution, this is not observed. While it is possible that this is obscured by the broad $\mathrm{C}=\mathrm{O}$ mode shown in Fig. 2(a), it is significantly more likely that these protons will have exchanged in a deuterated solvent leading to a large shift of the $\mathrm{NH}_{2}$ band to lower frequency. Indeed, our DFT calculations show that the $\mathrm{NH}_{2}$ bend moves to around $1300 \mathrm{~cm}^{-1}$ upon deuteration, well out of the region of interest here. This would also be consistent with other DFT studies, which predicted solvent $\mathrm{H}$-bonding interactions with the protons of the $\mathrm{NH}-\mathrm{NH}_{2}$ moiety. ${ }^{25}$ 
In further support of this, an FTIR spectrum of INH in DMSO (see supporting information, Fig. $\mathrm{S}^{32}$ ) showed a much narrower $\mathrm{C}=\mathrm{O}$ stretching mode than that observed in $\mathrm{D}_{2} \mathrm{O}$, located at $1660 \mathrm{~cm}^{-1}$, alongside a shoulder near $1630 \mathrm{~cm}^{-1}$. The latter feature would be consistent with the $\mathrm{NH}_{2}$ peak being present under conditions where the protons could not exchange. In addition, the broad feature assigned to the $\mathrm{CN}$ stretch/ND bend observed at $1447 \mathrm{~cm}^{-1}$ in deuterated solution appears at the higher frequency of $1540 \mathrm{~cm}^{-1}$ in DMSO. Given the similarity of this mode to the amide II'/II mode of the peptide link, this type of isotopic shift is consistent with what would be expected upon $\mathrm{H} / \mathrm{D}$ exchange of the $\mathrm{NH}-\mathrm{NH}_{2}$ group. The modes identified with the pyridine ring were observed to be less sensitive to changes in solvent or to $\mathrm{D} / \mathrm{H}$ exchange as would be expected. Henceforth, and in Table 1, we refer to the hydrazide unit in its deuterated $\left(\mathrm{ND}-\mathrm{ND}_{2}\right)$ form when discussing data from $\mathrm{D}_{2} \mathrm{O}$ solutions.

In light of the question regarding the presence or otherwise of the intramolecular $\mathrm{H}$-bond in INH, it is interesting to note that changing from DMSO to $\mathrm{D}_{2} \mathrm{O}$ solution causes a large broadening and red-shift in the $\mathrm{C}=\mathrm{O}$ stretching transition, which is not attributable to deuteration. This is however consistent with a greater degree of solvent $\mathrm{H}$-bonding to the $\mathrm{C}=\mathrm{O}$ stretching vibration in $\mathrm{D}_{2} \mathrm{O} v s$ DMSO. Thus, even in the event that an intramolecular H-bond is present in INH dissolved in DMSO and that this remains in $\mathrm{D}_{2} \mathrm{O}$, it would seem not to be at the exclusion of $\mathrm{H}$-bonding to the solvent. Temperature dependent FT-IR experiments were also performed on INH in $\mathrm{D}_{2} \mathrm{O}$ (see Fig. $\mathrm{S}^{32}$ ). These indicated no major changes in the spectroscopy of INH up to $80{ }^{\circ} \mathrm{C}$ other than the progressive blue shift of the $\mathrm{C}=\mathrm{O}$ peak that would be anticipated from reduced strength $\mathrm{H}$ bonding as the solvent temperature increased. This would seem to support the notion that a significant contribution to the $\mathrm{C}=\mathrm{O}$ lineshape is due to $\mathrm{H}$-bonding with the solvent in the aqueous solution. 
Finally, it is important to consider the fact that, in the crystalline phase, INH in known to undergo intermolecular H-bonding via the $\mathrm{CO}-\mathrm{NH}-\mathrm{NH}_{2}$ unit. ${ }^{26}$ This has been shown to cause significant changes in the IR spectrum in the region considered here ${ }^{24}$ but the solution-phase spectra do not indicate contributions from anything other than monomeric INH. To further confirm this, FT-IR spectra were obtained in $\mathrm{D}_{2} \mathrm{O}$ at a range of concentrations down to $30 \mathrm{mM}$ with no observable change in the band shapes or positions.

IR pump-probe spectroscopy: IR pump-probe spectroscopy was used to determine the vibrational relaxation timescales for each of the modes of INH in the $1400-1700 \mathrm{~cm}^{-1}$ region. Representative examples of the temporal dependencies of the peaks observed are shown in Fig. 3. The dynamics of the $\mathrm{v}=0-1\left(1644 \mathrm{~cm}^{-1}\right)$ and $\mathrm{v}=1-2\left(1633 \mathrm{~cm}^{-1}\right)$ transitions of the CO stretching vibration of INH are depicted in Fig. 3(a) while Fig. 3(b) shows the results for the corresponding peaks relating to the band at $1447 \mathrm{~cm}^{-1}$ in the FT-IR spectrum that is assigned to $\mathrm{CN}$ stretching/ND bending mode of the CO-ND-ND 2 group. In the case of the $\mathrm{CO}$ stretching vibration (Fig. 3(a)) the two peaks observed were found to decay in a manner that was well-represented by a single exponential function with a decay time constant of $1.19 \pm 0.07$ and $1.21 \pm 0.06$ ps for the $\mathrm{v}=0-1$ and $\mathrm{v}=1-2$ transitions respectively, revealing the vibrational lifetime of the $\mathrm{v}=1$ state to be $1.2 \mathrm{ps}$. In the case of the $\mathrm{CN}$ stretching/ND bending transition, a value of $1.0 \mathrm{ps}$ was obtained.

Interestingly, the pump-probe data showed that all of the peaks in the region of the spectrum studied showed similar fast vibrational relaxation dynamics with values on the order of 1-2 ps recovered in all cases. The longest-lived of these was found to be the pyridine ring vibration located at $1555 \mathrm{~cm}^{-1}$ for which a value of $1.9 \mathrm{ps}$ was measured. Due to the overlap of some spectral features it was not possible to extract accurate parameters for the $\mathrm{v}=0-1$ and $\mathrm{v}=1-2$ transitions of all modes but for those where this was achieved the agreement between the two 
features was good, as would be expected. The values obtained for the vibrational lifetimes of the individual modes of INH are given in Table 1.

2D-IR spectroscopy: 2D-IR spectra of INH are shown in Fig. 4(a-f) for a range of waiting times alongside the linear spectrum for reference. The 2D-IR spectra were normalized to the dominant diagonal transition at $1644 \mathrm{~cm}^{-1}$ but scaled to display the smaller off-diagonal features more clearly, hence the apparent saturation of the features due to the $\mathrm{C}=\mathrm{O}$ stretching mode in the figure. As expected, each of the peaks visible in the linear IR spectrum in this region give rise to a negative peak on the diagonal of the $2 \mathrm{D}-\mathrm{IR}$ spectrum assignable to the $\mathrm{v}=0-1$ transition of the mode in question. This is accompanied in all cases by a positive feature shifted to lower probe frequency arising from the corresponding $\mathrm{v}=1-2$ transition; the shift is attributable to the anharmonicity of the vibrational potential.

The 2D-IR spectra provide indications of vibrational coupling between all of the modes in this region of the spectrum. This is manifest in the presence of off-diagonal features linking each of the diagonal peaks to the remaining modes (dashed lines in Fig. 4) even at the earliest waiting times measured. While this might be considered surprising, the aromatic $\pi$-electron system of the pyridine ring would be expected to be conjugated with the $\pi$-orbitals of the adjacent amide-type moiety and, as such, this provides a potential vehicle for coupling of the modes across the molecule.

In addition to signatures of vibrational coupling, a progressive increase in the intensity of the offdiagonal peaks relative to the diagonal features can be seen as the waiting time increases in Fig. $4 .{ }^{33}$ The amplitudes of a selection of these off-diagonal peaks, as a ratio to the height of their respective diagonal features, are plotted against the experimental waiting time in Fig. 5. It can be 
seen from the Figure that the peaks are non-zero as the waiting time approaches zero, consistent with the effects of vibrational coupling discussed above. The subsequent increase in amplitude of the off-diagonal peaks also suggests that further dynamics are contributing to their behavior however. There exist a number of possible explanations for this effect including energy transfer, and chemical exchange. These have been described in detail elsewhere. ${ }^{7}$

In the case of vibrational energy transfer, increases in the amplitudes of off-diagonal peaks can be attributed to resonant vibrational population transfer between vibrational modes, facilitated by the low frequency modes of the solvent, which act as 'bath' modes. In $\mathrm{D}_{2} \mathrm{O}$, the broad density of states at low frequency will be capable of acting as a bath for resonant transfer between the INH modes considered here which, in general, are separated by less than $200 \mathrm{~cm}^{-1} .{ }^{34}$ However, offdiagonal peaks can also be influenced by a more generic relaxation-induced heat effect involving relaxation to lower frequency vibrations. It is thus instructive to consider which of these mechanisms is responsible via examination of the relative relaxation dynamics of the diagonal and off-diagonal features.

The absolute timescales observed for rising behavior of the individual off-diagonal peaks showed some variation. For example, the peak corresponding to excitation of the $\mathrm{C}=\mathrm{O}$ stretching mode at $1644 \mathrm{~cm}^{-1}$ and detection at the frequency of the $\mathrm{CN}$ stretch/N-D bend transition near $1447 \mathrm{~cm}^{-1}$ showed a 1.7 ps rise time (Fig 5(a)). The off-diagonal peak corresponding to the reverse process exhibited slightly faster dynamics (1.1 ps, Fig $5(\mathrm{~b}))$. While it is noted that these values do not correspond to the rates that would be expected via detailed balance, it must be noted that the short vibrational lifetime of the modes involved leads to uncertainties in the absolute values (Fig 5(a)). Overall, the evidence for energy flow in both directions and the similar magnitude of the values observed to that of the vibrational lifetimes of the excited transitions suggests that efficient 
vibrational energy transfer between these coupled vibrations is likely to form a significant part of the relaxation mechanism of INH.

In the case of pairs of modes where one was associated with the pyridine ring and the other with the CO-ND-ND ${ }_{2}$ ring substituent, efficient transfer of energy was still observed. The peak corresponding to excitation of the $\mathrm{CN}$ stretch/N-D bend mode at $1447 \mathrm{~cm}^{-1}$ and detection at the frequency of the ring vibration at $1555 \mathrm{~cm}^{-1}$ showed a rise time of $\sim 3.3 \mathrm{ps}$ (Fig 5(b)). Similarly, the off-diagonal peaks between the $\mathrm{C}=\mathrm{O}$ stretch (excitation) and the same ring mode (detection) required $\sim 1$ ps (Fig 5(b)), though that between the $\mathrm{C}=\mathrm{O}$ stretch (excitation) and the ring mode at $1502 \mathrm{~cm}^{-1}$ (detection) required $3.1 \mathrm{ps}$. Once again, the uncertainty of the absolute values was influenced by the detection window and the small amplitude of the $1555 \mathrm{~cm}^{-1}$ transition. The latter feature was common to several off-diagonal peaks, restricting a complete analysis of the dynamics observed; the evidence for rapid energy transfer is clearly present however.

Overall, from the 2D-IR data, it is clear that energy transfer processes are occurring between vibrational modes of INH assignable to both the pyridine ring and ring substituent moiety with a time constant in the region of 1-3 ps. This, in conjunction with the similar vibrational lifetimes of the modes is indicative of efficient vibrational relaxation across the molecule. It is not possible to definitively assign this to direct resonant transfer, which would demonstrate kinetics in agreement with detailed balance, but the presence of strong coupling of the modes through the aromatic and extended $\pi$-system would be expected to provide a route for this to occur. This is also supported by the observation that the anisotropy parameters of the peaks observed in the IR pump-probe spectra decreased with a time constant in the region of the vibrational relaxation times observed $\left(\mathrm{Fig} \mathrm{S}^{32}\right.$ ). Such a timescale is too fast to be attributed to molecular rotation and is assigned to the effects of rapid vibrational energy transfer. 
It is noted that the increase in amplitude of off-diagonal features in the 2D-IR spectrum can also arise due to chemical exchange, i.e. from interconversion of populations. ${ }^{35}$ However, the timescales accessed by the 2D-IR spectra reported here are generally too short to observe such phenomena, except in the cases of H-bonding exchange which will be discussed below. The possibility of INH existing in multiple conformers has been discussed, especially in relation to cistrans isomerization of the CO-NH-NH 2 group (Fig. 1). The two conformers are predicted by gasphase DFT calculations to be separated by $20 \mathrm{kJmol}^{-1}$ in terms of free enthalpy but the energy barrier for cis to trans interconversion was predicted to be in excess of $50 \mathrm{kJmol}^{-1}$ and it was concluded that the majority of the INH population existed in a single, cis conformer under room temperature conditions (Fig. 1b). ${ }^{24}$ Furthermore, such an energy barrier would indicate that interconversion would be expected to be slow on the timescale of our experiments.

Spectral diffusion of the $\mathbf{C}=\mathbf{O}$ stretching vibration: In addition to the relaxation dynamics of the peaks observed in the 2D-IR spectra shown in Fig. 4, it is noticeable that the 2D shape of the diagonal peak attributable to the $\mathrm{C}=\mathrm{O}$ stretching vibrational mode of INH changes as a function of the waiting time. In particular, it alters from diagonally-elongated at short waiting times to more circular as the waiting time increases.

This effect has been described in detail previously ${ }^{10,12,13,18,36,37}$ and is assigned to spectral diffusion associated with the inhomogeneous broadening of the transition. In this case, of a water-solvated $\mathrm{C}=\mathrm{O}$ bond, the effect is caused, primarily, by the motion of solvent molecules leading to fluctuations in the strength of $\mathrm{H}$-bonds between water and the $\mathrm{C}=\mathrm{O}$ oscillator. ${ }^{8}$ At waiting times that are short on the timescale of the water dynamics, a correlation of pump and probe frequency is observed in the $2 \mathrm{D}$ lineshape. At longer waiting times, the H-bond environment has evolved 
between excitation and detection events such that the memory of the initial state of the system is lost and the peak becomes more circular in shape.

In the case of the $\mathrm{C}=\mathrm{O}$ stretching vibration of $\mathrm{INH}$, these dynamics were extracted using the Centre-Line Slope (CLS) method, that has been shown to report on the dynamics of the frequency-frequency correlation function of a given vibrational mode. ${ }^{38}$ The results of this process are shown in Fig. 6 where the inverse of the gradient of the CLS is plotted against the experimental waiting time. This in turn was fit to an exponential decay function with a static offset, yielding a value of $0.6 \mathrm{ps}$ for the decay time and an offset of $\sim 0.15$.

These results differ somewhat from what might have been anticipated based on previous studies of similar systems. In the case of amide I modes of peptide linkages or of simple amide-containing molecules such as $N$-methylacetamide, it is widely accepted that the dynamics of water molecules in the local vicinity lead to dynamics on two timescales; fast (sub $100 \mathrm{fs}$ ) processes associated with molecular librations of water alongside dynamics with timescales of around $1 \mathrm{ps}$, which are attributed to H-bond fluctuations. $8,12,13,39,40$

While the $\mathrm{C}=\mathrm{O}$ mode of INH is not a pure amide, one would expect similar solvation behavior of the CO-ND-ND 2 moiety in comparison to these systems. Indeed, the results for INH indicate that fast processes are contributing to the $2 \mathrm{D}$ lineshape of the $\mathrm{C}=\mathrm{O}$ mode from the fact that the CLS does not tend towards a value of unity at zero waiting time as would be expected for the limiting case of a strongly inhomogeneously broadened lineshape featuring no dynamics faster than the time resolution of the experiment. This effect arises from fast dynamics and the homogeneous linewidth of the transition and the value of around 0.4 is in reasonable agreement with previous work on amide I transitions under aqueous solvation conditions. ${ }^{8}$ However, the decay time of 0.6 
ps is faster than would typically be expected and for simple amide systems it is unusual to observe a static component in the data as shown in Fig. 6 . In this, the short lifetime of the $\mathrm{C}=\mathrm{O}$ stretching vibration may play a part, limiting the useful range of waiting times at which the CLS could be reliably extracted. However, it was clear that the value of the CLS did not tend to zero and that there is some longer timescale component to the data that is manifest as residual inhomogeneous broadening at waiting times exceeding 2-3 ps.

The major difference between systems such as N-methylacetamide and simple peptides and INH is the proposed existence of an intramolecular H-bond between the $\mathrm{NH}_{2}$ group and the carbonyl oxygen. In cases where the effect of such a structure on the spectral diffusion dynamics or linebroadening mechanisms have been reported, an intramolecular H-bond tends to increase the rate of spectral diffusion ${ }^{37,41}$ and this has been attributed to the stronger, localised interaction arising as compared to generic solvation H-bonding from mobile water. ${ }^{39,}{ }^{42}$ In addition, static components have been observed in the spectral diffusion dynamics of peptide modes involved in such interactions. ${ }^{42}$ These have been assigned to longer-lived structures giving rise to inhomogeneity in the linewidth over a longer period.

One possible explanation of these observations is that the spectral diffusion dynamics of the $\mathrm{C}=\mathrm{O}$ mode of INH are being influenced by the presence of an intramolecular $\mathrm{H}$-bond to the $\mathrm{ND}_{2}$ group. However, as was observed in the section on FT-IR spectroscopy, this would not appear to be occurring to the exclusion of interactions with the solvent, though it would seem to have an influence on the solvation dynamics observed. It is plausible that both interactions exist and are present as contributions to the breadth of the $\mathrm{C}=\mathrm{O}$ stretching vibration observed. In this case, one would expect a range of frequencies corresponding to the sub-ensemble of INH molecules in the $\mathrm{C}=\mathrm{O} \cdots \mathrm{D}_{\text {intra }}$ state, which would be centered at a slightly lower frequency than a similar 
contribution from the $\mathrm{C}=\mathrm{O} \cdots \mathrm{D}_{\text {solvent }}$ sub-ensemble. The separation of the center frequencies would be determined by the relative strengths of the intramolecular and solvent H-bonds, as predicted by DFT calculations (Fig 2(b)) and the spectral range of the two sub-ensembles would be expected to overlap to some degree. If exchange between the two sub-ensembles were slow on the experimental timescale, then one might expect to observe diagonal elongation of the $2 \mathrm{D}$ lineshape at longer waiting times because of the existence of two partially overlapping diagonal features rather than a single one. As the waiting time approached the exchange time one would expect to see off-diagonal peaks or, given the frequency separation involved, anti-diagonal broadening of the lineshape arising from exchange between the two sub-ensembles. The data obtained here does not categorically rule out this possibility but we have observed no clear indication in support of this: the $\mathrm{C}=\mathrm{O}$ stretching vibration has been well-represented by a single $1 \mathrm{D}$ or $2 \mathrm{D}$ Gaussian lineshape function, depending on the experiment, under all conditions studied. This would suggest that the intramolecular H-bond and solvent H-bond sub-ensembles are not well-separated in terms of frequency, leading to the dynamics observed.

\section{Concluding Remarks}

The results of the experiments described suggest that INH exists in monomeric form in deuterated solution with complete $\mathrm{H} / \mathrm{D}$ exchange of the protons of the $\mathrm{NH}-\mathrm{NH}_{2}$ moiety. In addition, the results of ultrafast pump-probe and 2D-IR spectroscopy measurements indicate that the vibrational modes of the INH molecule occurring in the $1400-1700 \mathrm{~cm}^{-1}$ region of the spectrum are coupled. As these modes are assignable to motions involving both the pyridine ring and CO-ND-ND 2 unit, this coupling is suggested to be mediated via the interactions of $\pi$-orbital systems of the aromatic ring and adjacent carbonyl group. This situation also facilitates efficient vibrational energy transfer between modes located on the ring and CO-ND-ND 2 substituent, 
leading to short vibrational lifetimes and enhancements of off-diagonal peak amplitudes with respect to the diagonal peaks as the experimental waiting time increases.

Spectral diffusion measurements carried out on the $\mathrm{C}=\mathrm{O}$ stretching vibration showed faster dynamics than would be expected for an amide CO stretch under conditions of aqueous solvation along with evidence of longer-lived structures that contributed to the inhomogeneity of the transition. This has been tentatively attributed to contributions from an intramolecular H-bond involving the $\mathrm{CO}$ and $\mathrm{ND}_{2}$ groups of the $\mathrm{INH}$ ring substituent, though linear IR measurements under a range of solvation conditions indicate that H-bonding to the solvent also plays a role in the spectroscopy of the CO stretching transition.

In light of the need for a spectroscopic probe of INH binding to its target protein InhA, these results suggest that some scope exists for INH to be useful. The main challenge to be addressed would be the spectral overlap of the $\mathrm{C}=\mathrm{O}$ stretch with the amide I band of the protein, however, isotope labelling of the $\mathrm{C}=\mathrm{O}$ of INH (to give ${ }^{13} \mathrm{C}={ }^{18} \mathrm{O}$ ) would perhaps be more straightforward than that for a protein and this might serve to circumvent this problem. Should this be achievable, the CO mode of INH has demonstrated that it is intense and spectrally, if not dynamically, wellseparated from other transitions due to the ring modes of INH and that it is sensitive to the dynamics of its immediate chemical environment. The short lifetime of the $\mathrm{C}=\mathrm{O}$ mode would be inhibiting but $\mathrm{H}$-bond dynamics are accessible and the loss of the $\mathrm{NH}-\mathrm{NH}_{2}$ moiety on activation to form the drug molecule with NADH may serve to increase this slightly. Additional unwanted complication may arise from the overlap of INH transitions with the complex spectroscopy of the NAD molecule but as it is not possible to extract this adduct in stable form this would have to be determined under conditions of binding to the protein. ${ }^{22}$ 


\section{Acknowledgements}

Funding from The Leverhulme Trust (RPG248) for this work is gratefully acknowledged by NTH, PAH and DJS. The authors would also like to acknowledge support from the STFC for access to the Central Laser Facility.

\section{References}

1. Klopman, G.; Fercu, D.; Jacob, J., Chem Phys, 204 181-193, (1996)

2. Favila, A.; Gallo, M.; Glossman-Mitnik, D., Journal of Molecular Modeling, 13 505-518, (2007)

3. Rozwarski, D. A.; Grant, G. A.; Barton, D. H. R.; Jacobs Jr, W. R.; Sacchettini, J. C., Science, 279 98, (1998)

4. $\quad$ Rawat, R.; Whitty, A.; Tonge, P. J., Proc Nat Acad Sci, 100 13881, (2003); Almeida Da Silva, P. E.; Palomino, J. C., Journal of Antimicrobial Chemotherapy, 66 1417-1430, (2011)

5. Zhang, Y.; Heym, B.; Allen, B.; Young, D.; Cole, S., Nature, 358 591-593, (1992)

6. Dessen, A.; Quemard, A.; Blanchard, J. S.; Jacobs, W. R.; Sacchettini, J. C., Science, 267 1638-1641, (1995); Dye, C.; Scheele, S.; Dolin, P.; Pathania, V.; Raviglione, M. C., JAMA, 282 $677,(1999)$

7. Adamczyk, K.; Candelaresi, M.; Robb, K.; Gumiero, A.; Walsh, M. A.; Parker, A. W.; Hoskisson, P. A.; Tucker, N. P.; Hunt, N. T., Meas Sci Tech, 23 062001, (2012); Hunt, N. T., Chem Soc Rev, 38 1837-1848, (2009); Hochstrasser, R. M., Proc Nat Acad Sci, 104 14190, (2007); Ganim, Z.; Chung, H. S.; Smith, A. W.; Deflores, L. P.; Jones, K. C.; Tokmakoff, A., Accts Chem Res, 41 432-441, (2008); Hamm, P.; Zanni, M. T., Concepts and Method of 2D Infrared Spectroscopy. Cambridge University Press: Cambridge, 2011.

8. Ghosh, A.; Hochstrasser, R. M., Chem Phys, 390 1-13, (2011) 
9. Moran, S. D.; Woys, A. M.; Buchanan, L. E.; Bixby, E.; Decatur, S. M.; Zanni, M. T., Proc Nat Acad Sci, 109 3329-3334, (2012); Tucker, M. J.; Abdo, M.; Courter, J. R.; Chen, J.; Brown, S. P.; Smith, A. B., III; Hochstrasser, R. M., Proc Nat Acad Sci, 110 17314-17319, (2013); Remorino, A.; Korendovych, I. V.; Wu, Y.; DeGrado, W. F.; Hochstrasser, R. M., Science, 332 1206-1209, (2011)

10. Woys, A. M.; Lin, Y.-S.; Reddy, A. S.; Xiong, W.; de Pablo, J. J.; Skinner, J. L.; Zanni, M. T., J Am Chem Soc, 132 2832-2838, (2010)

11. Middleton, C. T.; Marek, P.; Cao, P.; Chiu, C.-c.; Singh, S.; Woys, A. M.; de Pablo, J. J.; Raleigh, D. P.; Zanni, M. T., Nat Chem, 4 355-360, (2012); Strasfeld, D. B.; Ling, Y. L.; Gupta, R.; Raleigh, D. P.; Zanni, M. T., J Phys Chem B, 113 15679-15691, (2009); Shim, S. H.; Gupta, R.; Ling, Y. L.; Strasfeld, D. B.; Raleigh, D. P.; Zanni, M. T., Proc Nat Acad Sci, 106 6614-6619, (2009)

12. Kim, Y. S.; Liu, L.; Axelsen, P. H.; Hochstrasser, R. M., Proc Nat Acad Sci, 106 1775117756, (2009)

13. Ghosh, A.; Qiu, J.; DeGrado, W. F.; Hochstrasser, R. M., Proc Nat Acad Sci, 108 61156120, (2011)

14. Manor, J.; Mukherjee, P.; Lin, Y.-S.; Leonov, H.; Skinner, J. L.; Zanni, M. T.; Arkin, I. T., Structure, 17 247-254, (2009)

15. Kuroda, D. G.; Bauman, J. D.; Challa, J. R.; Patel, D.; Troxler, T.; Das, K.; Arnold, E.; Hochstrasser, R. M., Nat Chem, 5 174-181, (2013)

16. Thielges, M. C.; Chung, J. K.; Fayer, M. D., J Am Chem Soc, 133 3995-4004, (2011); Thielges, M. C.; Chung, J. K.; Axup, J. Y.; Fayer, M. D., Biochemistry, 50 5799-5805, (2011); Bagchi, S.; Thorpe, D. G.; Thorpe, I. F.; Voth, G. A.; Fayer, M. D., J Phys Chem B, 114 17187- 
17193, (2010); Bagchi, S.; Nebgen, B. T.; Loring, R. F.; Fayer, M. D., J Am Chem Soc, 132 18367-18376, (2010); Kim, S.; Chung, J. K.; Kwak, K.; Bowman, S. E. J.; Bren, K. L.; Bagchi, B.; Fayer, M. D., J Phys Chem B, 112 10054-10063, (2008); Ishikawa, H.; Kwak, K.; Chung, J. K.; Kim, S.; Fayer, M. D., Proc Nat Acad Sci, 105 8619-8624, (2008); Ishikawa, H.; Finkelstein, I. J.; Kim, S.; Kwak, K.; Chung, J. K.; Wakasugi, K.; Massari, A. M.; Fayer, M. D., Proc Nat Acad Sci, 104 16116-16121, (2007); Finkelstein, I. J.; Ishikawa, H.; Kim, S.; Massari, A. M.; Fayer, M. D., Proc Nat Acad Sci, 104 2637-2642, (2007)

17. Candelaresi, M.; Gumiero, A.; Adamczyk, K.; Robb, K.; Bellota-Antón, C.; Sangul, V.; Munnoch, J. T.; Greetham, G. M.; Towrie, M.; Hoskisson, P. A.; Parker, A. W.; Tucker, N. P.; Walsh, M. A.; Hunt, N. T., Org Biomol Chem, 11 7778-7788, (2013); Hunt, N. T.; Greetham, G. M.; Towrie, M.; Parker, A. W.; Tucker, N. P., Biochem J, 433 459-468, (2011)

18. Adamczyk, K.; Candelaresi, M.; Kania, R.; Robb, K.; Bellota-Antón, C.; Greetham, G. M.; Pollard, M. R.; Towrie, M.; Parker, A. W.; Hoskisson, P. A.; Tucker, N. P.; Hunt, N. T., PhysChemChemPhys, 14 7411-7419, (2012)

19. Simpson, N.; Adamczyk, K.; Hithell, G.; Shaw, D. J.; Greetham, G. M.; Towrie, M.; Parker, A. W.; Hunt, N. T., Faraday Discussions, in press 10.1039/C4FD00161C, (2015); Cheng, M.; Brookes, J. F.; Montfort, W. R.; Khalil, M., J Phys Chem B, 117 15804-15811, (2013) 20. Adamczyk, K.; Simpson, N.; Greetham, G. M.; Gumiero, A.; Walsh, M. A.; Towrie, M.; Parker, A. W.; Hunt, N. T., Chemical Science, 6 505-516, (2015)

21. Dutta, S.; Li, Y.-L.; Rock, W.; Houtman, J. C. D.; Kohen, A.; Cheatum, C. M., J Phys Chem B, 116 542-548, (2012); Nydegger, M. W.; Dutta, S.; Cheatum, C. M., J Chem Phys, 133 134506, (2010); Dutta, S.; Cook, R. J.; Houtman, J. C. D.; Kohen, A.; Cheatum, C. M., Analytical Biochemistry, 407 241-246, (2010); Bandaria, J. N.; Dutta, S.; Nydegger, M. W.; Rock, W.; 
Kohen, A.; Cheatum, C. M., Proc Nat Acad Sci, 107 17974-17979, (2010); Hill, S. E.; Bandaria,

J. N.; Fox, M.; Vanderah, E.; Kohen, A.; Cheatum, C. M., J Phys Chem B, 113 11505-11510, (2009); Kozinski, M.; Garrett-Roe, S.; Hamm, P., J Phys Chem B, 112 7645-7650, (2008)

22. Simpson, N.; Shaw, D. J.; Frederix, P. W. J. M.; Gillies, A. H.; Adamczyk, K.; Greetham, G. M.; Towrie, M.; Parker, A. W.; Hoskisson, P. A.; Hunt, N. T., J Phys Chem B, $11716468-$ $16478,(2013)$

23. Gunasekaran, S.; Sailatha, E.; Seshadri, S.; Kumaresan, S., Indian Journal of Pure \& Applied Physics, 47 12-18, (2009); Ymaz, A.; Bolukbasi, C.; Bakiler, M., Journal of Molecular Structure, 872 182-189, (2008)

24. Borba, A.; Gomez-Zavaglia, A.; Fausto, R., J Phys Chem A, 113 9220-9230, (2009)

25. Akalin, E.; Akyuz, S., Journal of Molecular Structure, 834 492-497, (2007)

26. Jensen, L. H., J Am Chem Soc, 76 4663-4667, (1954)

27. Greetham, G. M.; Burgos, P.; Cao, Q.; Clark, I. P.; Codd, P. S.; Farrow, R. C.; George, M. W.; Kogimtzis, M.; Matousek, P.; Parker, A. W.; Pollard, M. R.; Robinson, D. A.; Xin, Z.-J.; Towrie, M., Appl. Spectrosc, 64 1311-1319, (2010)

28. Deflores, L. P.; Nicodemus, R. A.; Tokmakoff, A., Opt Lett, 32 2966, (2007); Shim, S. H.; Zanni, M. T., PhysChemChemPhys, 11 748-761, (2009); Shim, S. H.; Strasfeld, D. B.; Ling, Y. L.; Zanni, M. T., Proc Nat Acad Sci, 104 14197, (2007)

29. Hunt, N. T.; Turner, A. R.; Wynne, K., J Phys Chem B, 109 19008, (2005)

30. Frisch, M. J. T., G. W.; Schlegel, H. B.; Scuseria, G. E.; Robb, M. A.; Cheeseman, J. R.; Scalmani, G.; Barone, V.; Mennucci, B.; Petersson, G. A.; Nakatsuji, H.; Caricato, M.; Li, X.; Hratchian, H. P.; Izmaylov, A. F.; Bloino, J.; Zheng, G.; Sonnenberg, J. L.; Hada, M.; Ehara, M.; Toyota, K.; Fukuda, R.; Hasegawa, J.; Ishida, M.; Nakajima, T.; Honda, Y.; Kitao, O.; Nakai, H.; 
Vreven, T.; Montgomery, Jr., J. A.; Peralta, J. E.; Ogliaro, F.; Bearpark, M.; Heyd, J. J.; Brothers, E.; Kudin, K. N.; Staroverov, V. N.; Kobayashi, R.; Normand, J.; Raghavachari, K.; Rendell, A.; Burant, J. C.; Iyengar, S. S.; Tomasi, J.; Cossi, M.; Rega, N.; Millam, N. J.; Klene, M.; Knox, J. E.; Cross, J. B.; Bakken, V.; Adamo, C.; Jaramillo, J.; Gomperts, R.; Stratmann, R. E.; Yazyev, O.; Austin, A. J.; Cammi, R.; Pomelli, C.; Ochterski, J. W.; Martin, R. L.; Morokuma, K.; Zakrzewski, V. G.; Voth, G. A.; Salvador, P.; Dannenberg, J. J.; Dapprich, S.; Daniels, A. D.; Farkas, Ö.; Foresman, J. B.; Ortiz, J. V.; Cioslowski, J.; Fox, D. J., Gaussian, Inc., Wallingford $C T, 2009,(2009)$

31. Andersson, M. P.; Uvdal, P., J Phys Chem A, 190 2937, (2005)

32. See Supplementary Material Document No........ for additional Figures

33. Stewart, A. I.; Clark, I. P.; Towrie, M.; Ibrahim, S.; Parker, A. W.; Pickett, C. J.; Hunt, N. T., J Phys Chem B, 112 10023, (2008)

34. Kenkre, V. M.; Tokmakoff, A.; Fayer, M. D., J Chem Phys, 101 10618, (1994)

35. Zheng, J.; Kwak, K.; Xie, J.; Fayer, M. D., Science, 313 1951, (2006); Cahoon, J. F.; Sawyer, K. R.; Schlegel, J. P.; Harris, C. B., Science, 319 1820, (2008)

36. Finkelstein, I. J.; Zheng, J. R.; Ishikawa, H.; Kim, S.; Kwak, K.; Fayer, M. D., PhysChemChemPhys, 9 1533-1549, (2007); Roberts, S. T.; Loparo, J. J.; Tokmakoff, A., J Chem Phys, 125 084502, (2006)

37. van der Vegte, C. P.; Knop, S.; Voehringer, P.; Knoester, J.; Jansen, T. L. C., J Phys Chem $B, 118$ 6256-6264, (2014)

38. Kwak, K.; Park, S.; Finkelstein, I. J.; Fayer, M. D., J Chem Phys, 127 124503, (2007)

39. Zanni, M. T.; Gnanakaran, S.; Stenger, J.; Hochstrasser, R. M., J Phys Chem B, 105 6520$6535,(2001)$ 
40. Zanni, M. T.; Asplund, M. C.; Hochstrasser, R. M., J Chem Phys, 114 4579-4590, (2001)

41. Knop, S.; Jansen, T. L. C.; Lindner, J.; Voehringer, P., PhysChemChemPhys, 13 46414650, (2011)

42. Park, J.; Hochstrasser, R. M., Chem Phys, 323 78-86, (2006) 


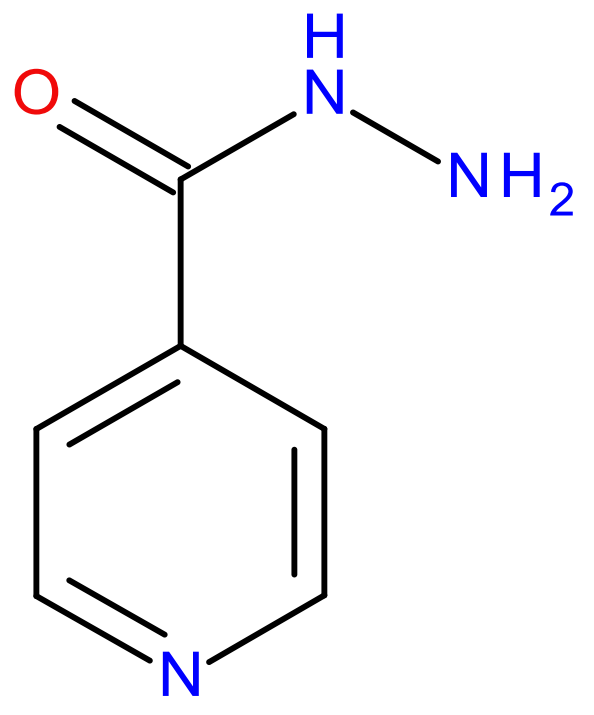

(a)

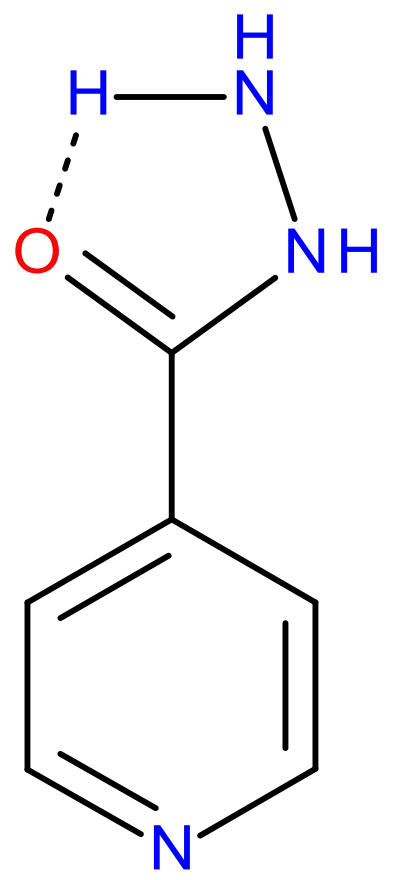

(b)

Figure 1: Diagrams of the molecular structure of isoniazid (INH) showing a) trans and b) cis isomers of the CO-NH-NH2 moiety. The proposed intramolecular H-bond discussed in the text is marked by a dashed line in b). 

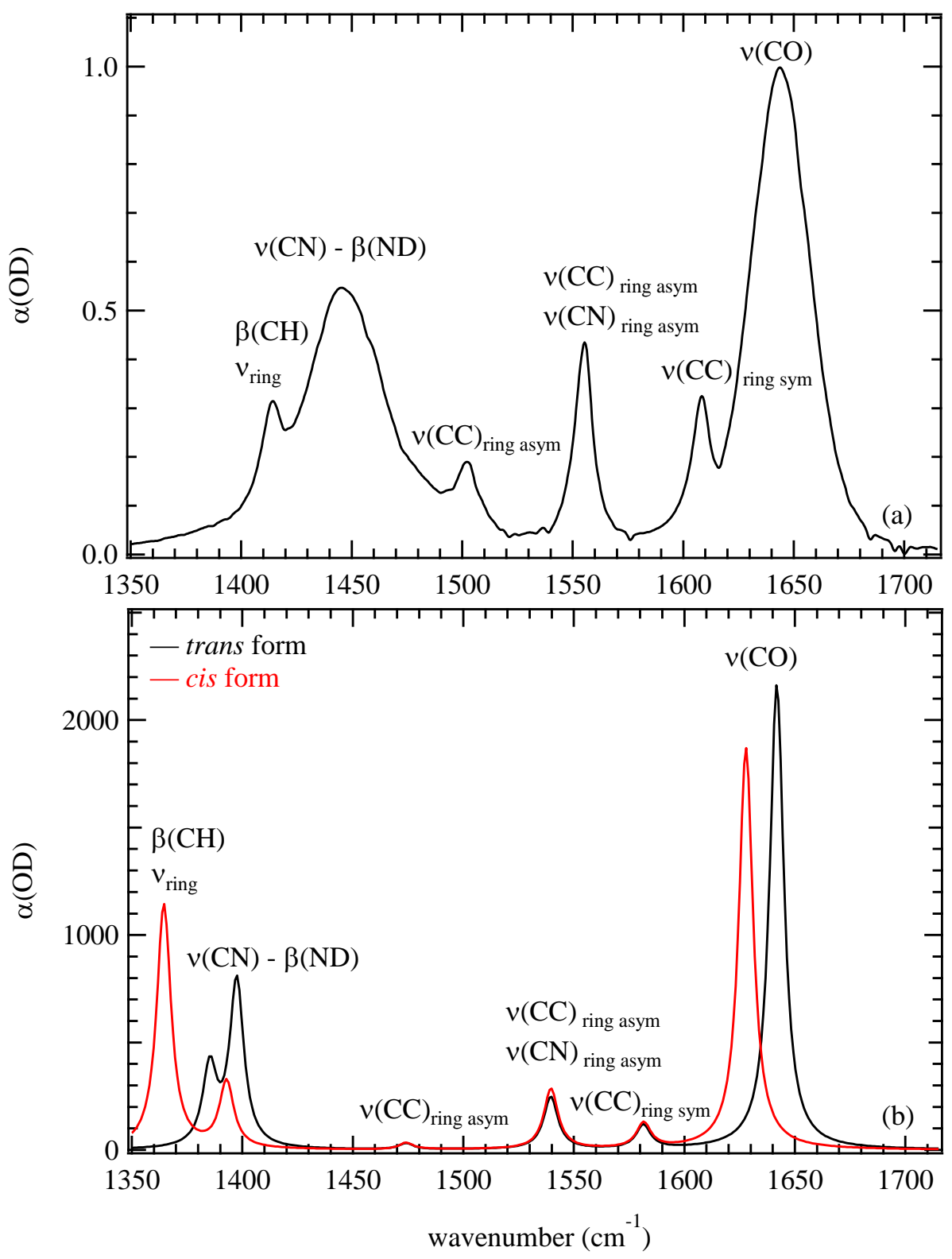

Figure 2: a) FTIR spectrum of INH at a concentration of $\sim 300 \mathrm{mM}$ in a $\mathrm{D}_{2} \mathrm{O}$ solution containing deuterated phosphate buffer at a $\mathrm{pD}$ of 7 (solvent background subtracted). The band assignments as discussed in the text and given in Table 1 are marked on the figure. $\alpha$ indicates absorbance. $b$ ) DFT calculated spectra for INH in the cis (red) and trans (black) forms. 
Table 1: Infrared spectroscopy data for $\mathrm{INH}$ in $\mathrm{D}_{2} \mathrm{O}$ solution at $\mathrm{pD} 7$ and results of Density Functional Theory calculations.

\begin{tabular}{|c|c|c|c|c|c|}
\hline $\begin{array}{l}\text { Frequency } \\
\left(\mathrm{cm}^{-1}\right)\end{array}$ & $\begin{array}{l}\text { Linewidth } \\
\left(\mathrm{cm}^{-1}\right)\end{array}$ & Assignment $^{a}$ & $\begin{array}{l}\text { DFT }^{\text {b }} \\
\left(\mathrm{cm}^{-1}\right)\end{array}$ & $\begin{array}{l}\text { DFT }^{\mathrm{c}} \\
\left(\mathrm{cm}^{-1}\right)\end{array}$ & $\begin{array}{l}\text { Vibrational } \\
\text { lifetime (ps) }\end{array}$ \\
\hline 1644 & $17.7 \pm 0.2$ & $v(\mathrm{CO})$ & 1628 & 1642 & $1.2 \pm 0.1$ \\
\hline 1608 & $3.9 \pm 0.1$ & $v(\mathrm{CC})_{\text {ring,sym }}$ & 1582 & 1582 & $0.9 \pm 0.1$ \\
\hline 1555 & $6.3 \pm 0.1$ & $v(\mathrm{CC}, \mathrm{CN})_{\text {ring,asym }}$ & 1540 & 1540 & $1.9 \pm 0.3$ \\
\hline 1502 & $4.7 \pm 0.5$ & $v(\mathrm{CC})_{\text {ring,asym }}$ & 1474 & 1474 & - \\
\hline 1447 & $20.3 \pm 0.5$ & $v(\mathrm{CN})-\beta(\mathrm{ND})$ & 1365 & 1398 & $1.0 \pm 0.1$ \\
\hline 1415 & $7.4 \pm 1.0$ & $v_{\text {ring }}, \beta(\mathrm{CH})$ & 1393 & 1385 & $0.9 \pm 0.1$ \\
\hline
\end{tabular}

a) $v$ indicates stretching vibration, $\beta$ indicates bending vibration

b) Based on cis structure Fig. 1(b)

c) Based on trans structure Fig. 1(a) 

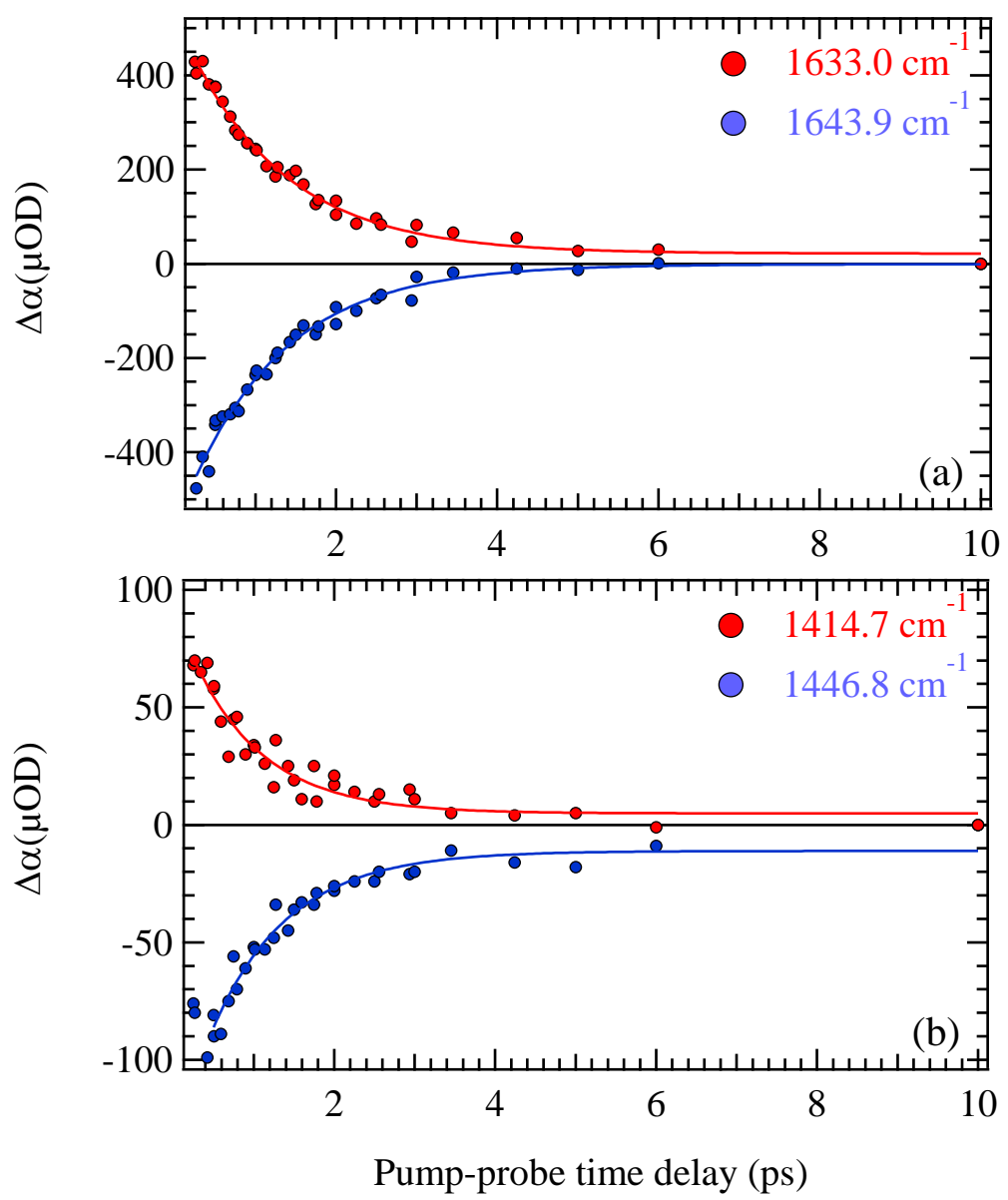

Figure 3: Vibrational dynamics of selected peaks observed in infrared pump-probe spectra of INH in $\mathrm{D}_{2} \mathrm{O}$ solutions: a) Temporal dependence of the $\mathrm{v}=0-1$ (blue) and $\mathrm{v}=1-2$ (red) transitions of the $\mathrm{C}=\mathrm{O}$ stretching vibration of $\mathrm{INH}$. The frequencies of the bands are given in the legends. b) $\mathrm{v}=0-1$ (blue) and $\mathrm{v}=1-2$ (red) transitions of the $\mathrm{C}-\mathrm{N}$ stretch/ND bending vibration of INH. 


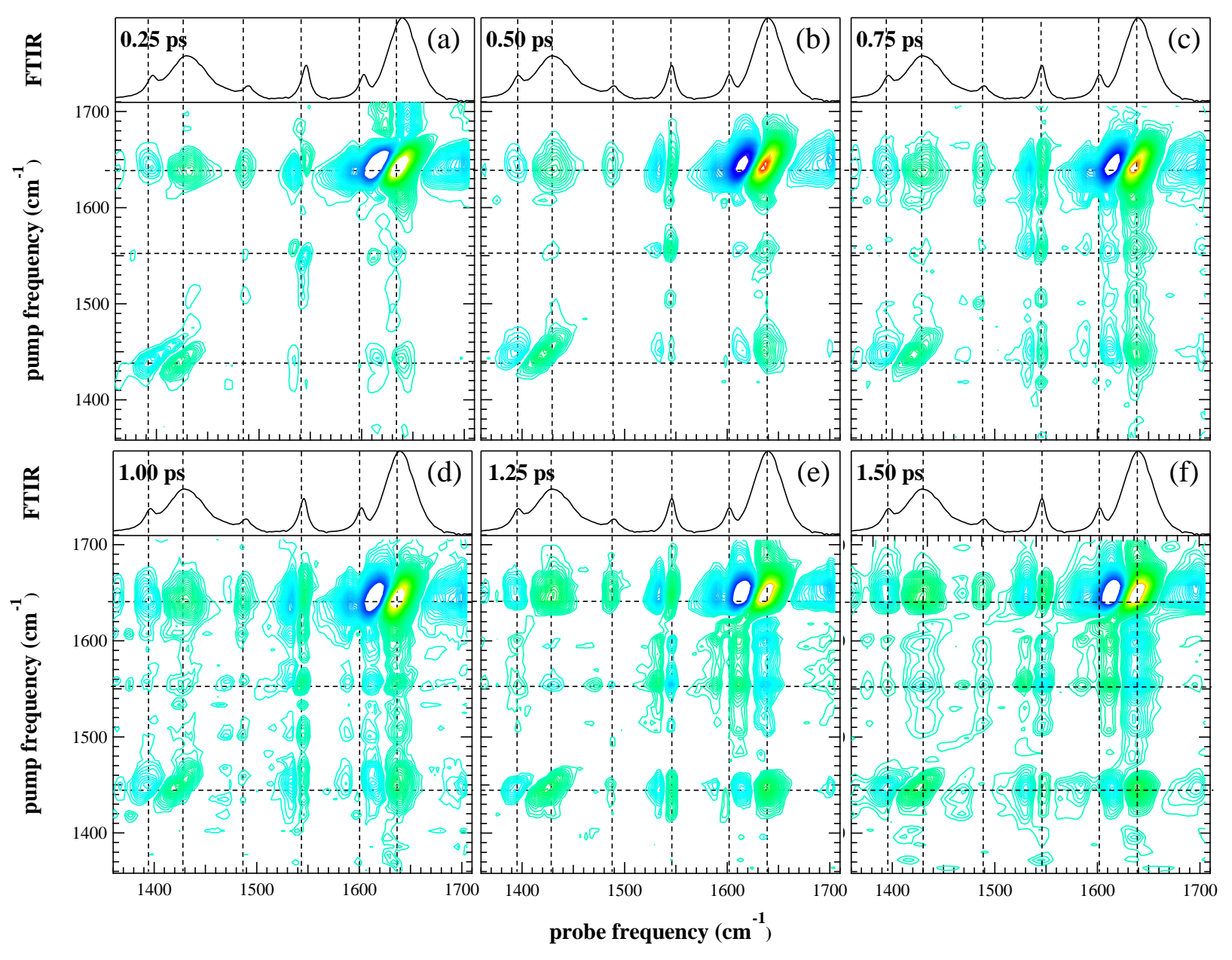

Figure 4: 2D-IR spectra of INH in $\mathrm{D}_{2} \mathrm{O}$ solution at a range of experimental waiting times. FTIR spectra are given in each case for reference. The waiting times are as shown in the Figs. Colour scale runs from red (negative) to blue (positive). Dashed lines are guides to indicate coupling patterns. 

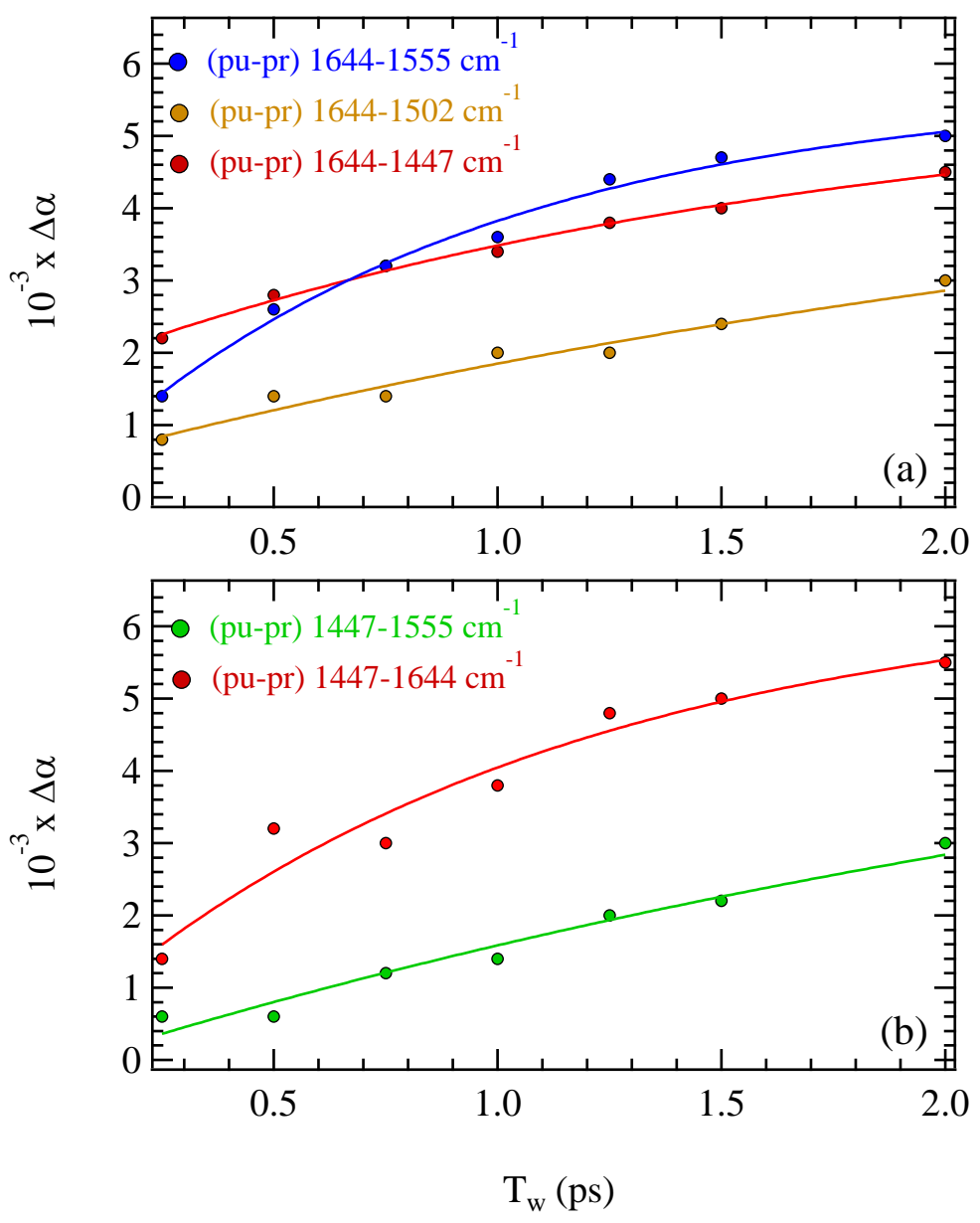

Figure 5: ( $a$ and b) Off-diagonal peak dynamics for selected 2D-IR spectral features from Fig 4 as identified in the legends. In all cases, points indicate experimental data while solid lines are fits to exponential functions. 


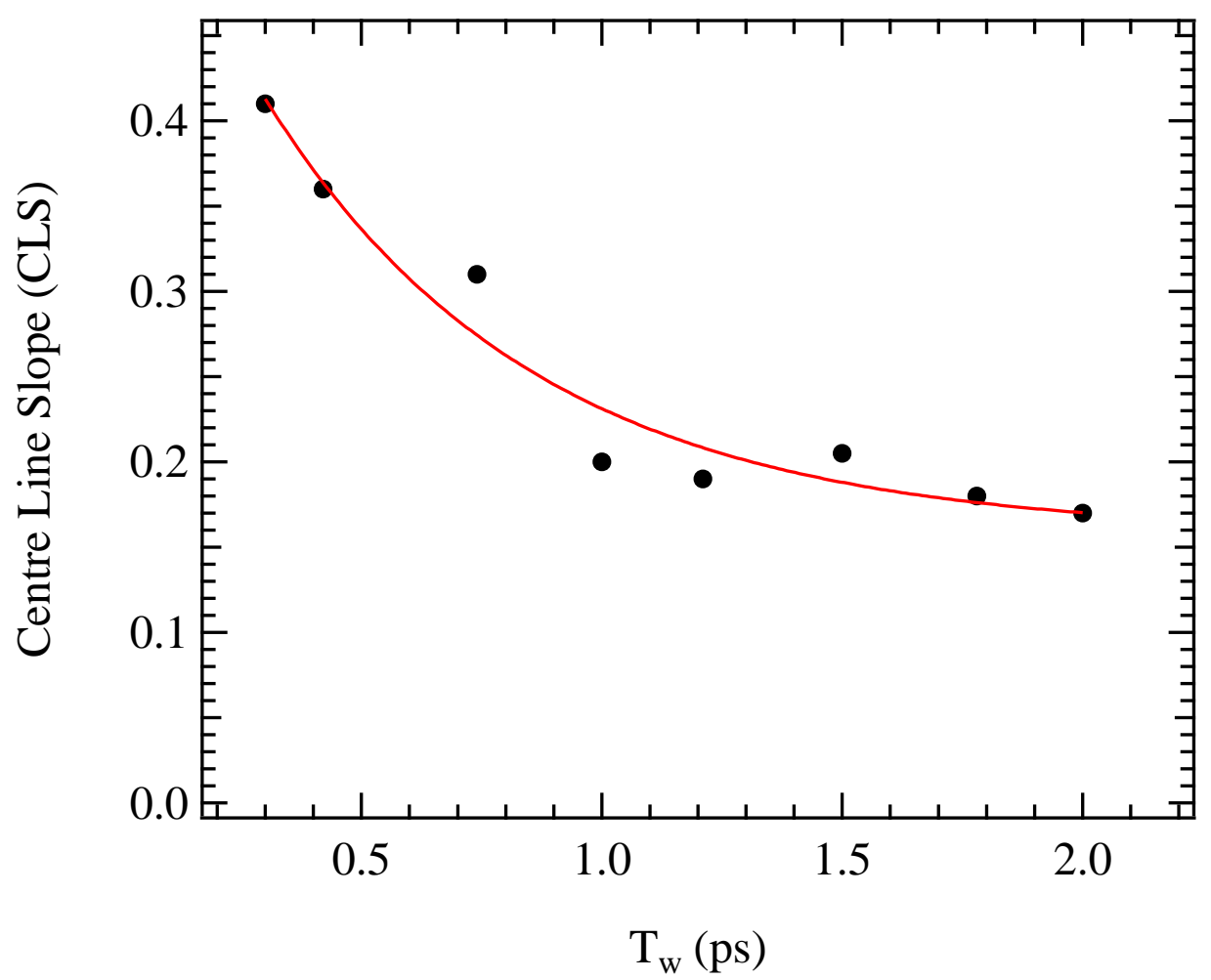

Figure 6: Spectral diffusion data obtained via the Centre line Slope method for the $C=O$ stretching vibrational mode of $\mathrm{INH}$ in $\mathrm{D}_{2} \mathrm{O}$ solution. Points indicate experimental data; solid line indicates a fit to an exponential function. 